\title{
Study on Finite Element Simulation Analysis of Dongxi Reservoir Concrete Arch Dam
}

\author{
Dongyu $\mathrm{Ji}^{1, \mathrm{a}}$, Weifang Zou ${ }^{2, \mathrm{~b}}$ \\ ${ }^{1}$ Hunan Urban Construction College, Xiangtan, Hunan Province 411101, P.R. China \\ ${ }^{2}$ Zhejiang Dahua Construction Group Co., LTD, Hangzhou, Zhejiang Province 310012, P.R. China \\ ahnjdy@126.com, b80231097@qq.com
}

Keywords: Dongxi reservoir, Concrete, Arch dam, Simulation analysis.

\begin{abstract}
Arch dam is a water retaining structure which has beautiful bodily form and reasonable structure form, in recent years, arch dam has been widely used. This paper adopts finite element method to carry out three-dimensional finite element simulation analysis for Dongxi reservoir concrete arch dam, researching variation law of the dam's stress and displacement in operational process. Research results show that, Dongxi reservoir concrete arch dam is reasonable structure, good mechanical performance, every index meets the requirements for design.
\end{abstract}

\section{Project summary}

Dongxi reservoir is located Fengqiao River, which is located Zhuji county in Zhejiang province. The main function of engineering is irrigation, it is comprehensive utilization water conservancy and hydropower engineering. The main buildings include concrete arch dam, water pipe and powerhouse, etc. The basin area that is controlled by dam is $17.5 \mathrm{~km}^{2}$, total reservoir storage capacity is 35.45 million $\mathrm{m}^{3}$. The dam is concrete arch dam, maximum dam high is $26 \mathrm{~m}$, effective dam high is $23 \mathrm{~m}$. maximum centre angle is $91^{\circ}$, minimum centre angle is $71^{\circ}$, thickness of dam bottom is $2 \mathrm{~m}$, thickness of dam crest is $1.1 \mathrm{~m}$, thickness-to-height ratio of arch dam's section is 0.09. River valley of dam site is V-shaped, gradient of two banks are about $50^{\circ} \sim 60^{\circ}$, the foundation of dam is coarse crumbs tuff.

\section{Calculation Model}

Model Parameters. Concrete strength grade of Dongxi reservoir arch dam is C20, elastic modulus $\mathrm{E}_{1}=25.5 \mathrm{GPa}^{[1]}$, Poisson ratio $\mu_{1}=0.167$, density $\gamma_{1}=24 \mathrm{kN} / \mathrm{m}^{3}$. The foundation of dam is tuff, elastic modulus $\mathrm{E}_{2}=17 \mathrm{GPa}^{[2]}$, Poisson ratio $\mu_{2}=0.28$.

Model Element. Concrete arch dam and bedrock structure model is divided by eight nodes isoparametric block element. The element is often applied to three-dimensional model of entity structure, it has plasticity, creep, expansion, stress rigidization, large deformation and large strain characteristics. It has eight nodes, each node has three translational degree of freedoms ${ }^{[3]}$.

Model size. Calculation model simulation range is listed below, calculation model along the river is $90 \mathrm{~m}$, transverse of the river is $108 \mathrm{~m}$, vertical direction is $76 \mathrm{~m}$. The simulation range of whole calculation model is $90 \mathrm{~m} \times 108 \mathrm{~m} \times 76 \mathrm{~m}$. Element division of dam and bedrock is shown in Fig.1.

Calculation Cases. Considering mechanical characteristics of dam structure in operating process[4], researching five calculation cases as follows. Case 1, dam weight, normal storage level, uplift pressure and tail water level, case 2, dam weight, design level, uplift pressure and tail water level, case 3, dam weight, design level, uplift pressure, tail water level and earthquake effect, case 4, dam weight, flood level, uplift pressure and tail water level, case 5, dam weight, flood level, uplift pressure, tail water level and earthquake effect. 
Analysis Path. In order to analyzing concrete arch dam of Dongxi reservoir, one analysis path is defined, on the upstream face of crown cantilever, choosing one calculation point every $1.74 \mathrm{~m}$ from dam bottom to dam crest, there are sixteen calculation points totally, these points assembled analysis path. Stress distribution of the path is provided in the paper.

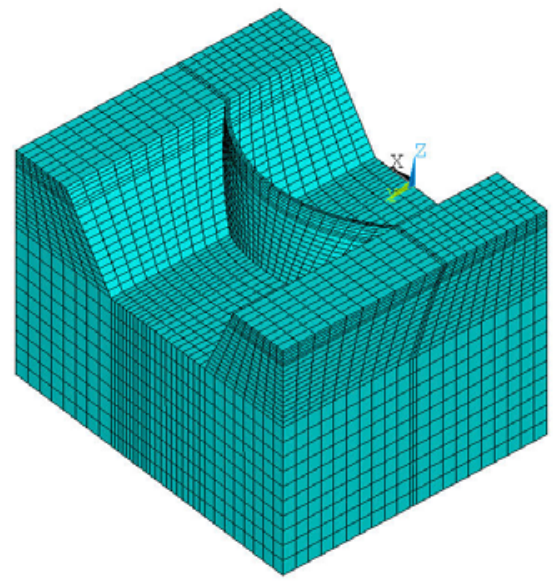

Fig.1 Element division of dam and bedrock

Stress Analysis. In order to researching stress distribution law of crown cantilever, obtaining circumferential and vertical stress variation curves of analysis path under various cases, the stress variation curves are shown from Fig.2 to Fig.3.

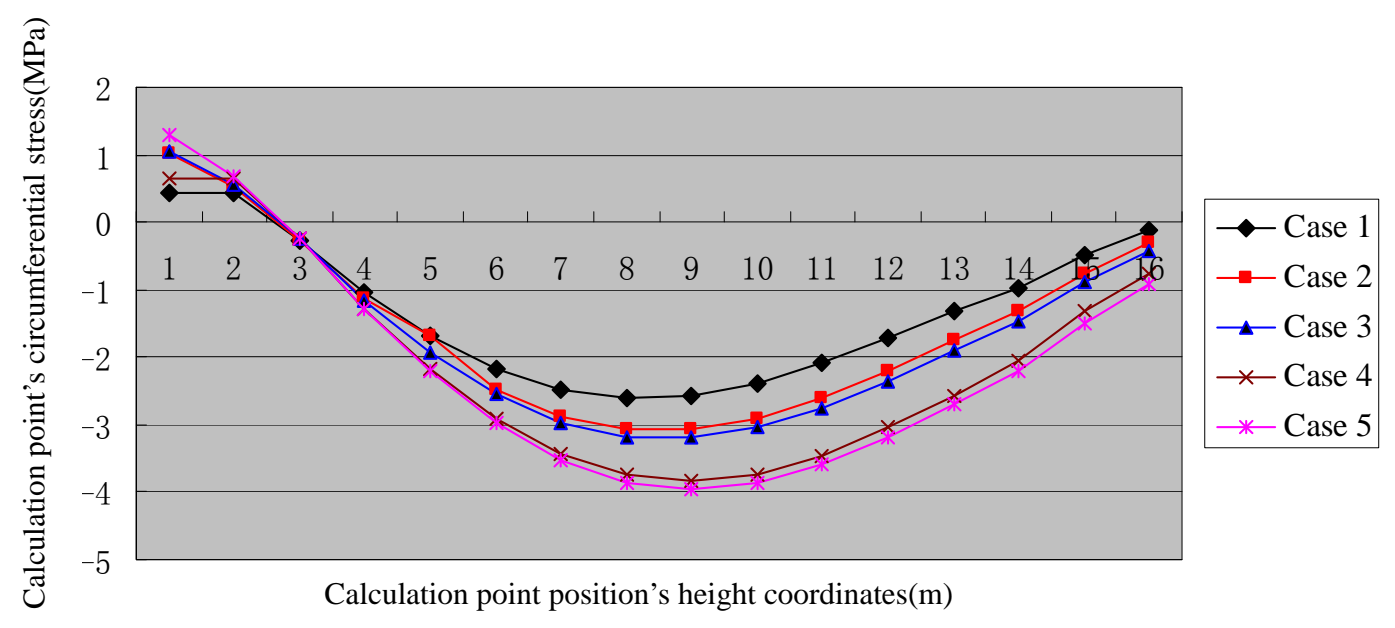

Fig.2 Circumferential stress variation curves of analysis path under various cases

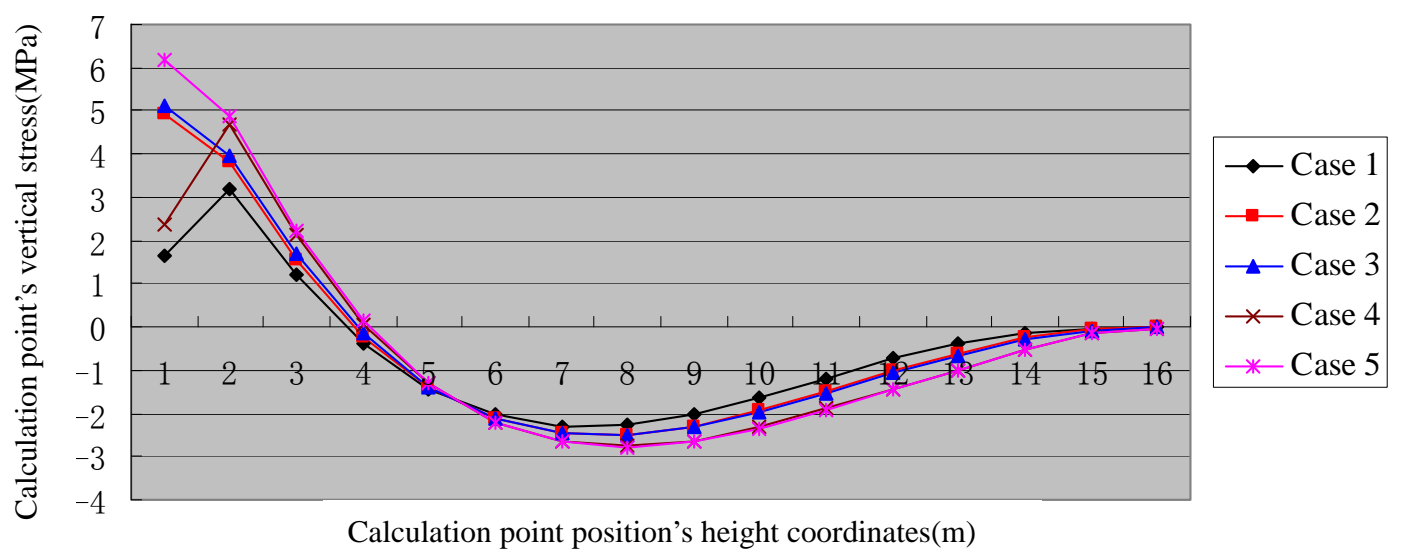

Fig.3 Vertical stress variation curves of analysis path under various cases

We can see from Fig.2 to Fig.3, under various cases, arch dam's circumferential and vertical stress of analysis path appears tensile stress. This is mainly because the effect of water pressure, arch dam's bottom appears stress concentration phenomenon. There appear larger circumferential 
and vertical compressive stress in the middle of arch dam. But circumferential and vertical stress is very small in the arch dam's crest, the stress values close to zero.

Cloud maps of arch dam's first principal stress under various cases are shown from Fig.4 to Fig.8.

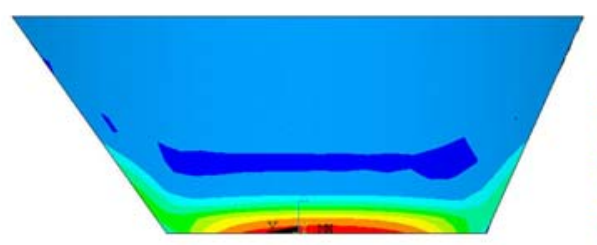

Fig.4 Cloud map of arch dam's first principal stress under case $1(\mathrm{~Pa})$

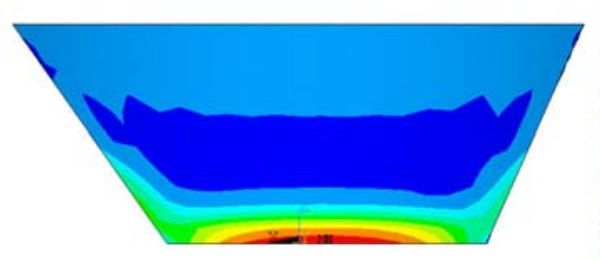

Fig.6 Cloud map of arch dam’s first principal stress under case 3(Pa)
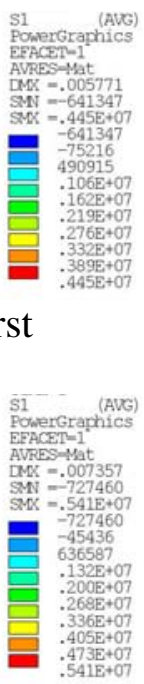

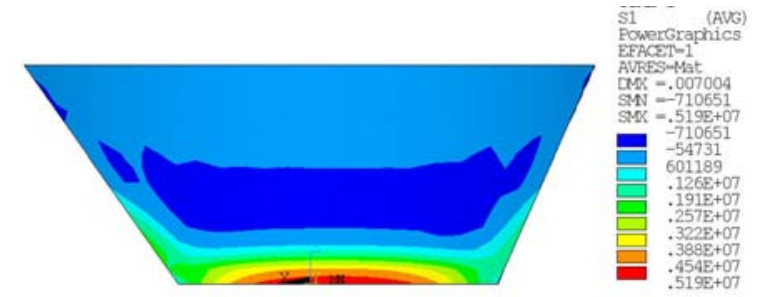

Fig.5 Cloud map of arch dam's first principal stress under case $2(\mathrm{~Pa})$

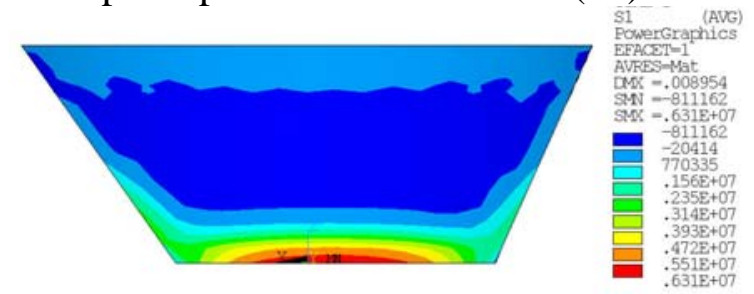

Fig.7 Cloud map of arch dam’s first principal stress under case $4(\mathrm{~Pa})$

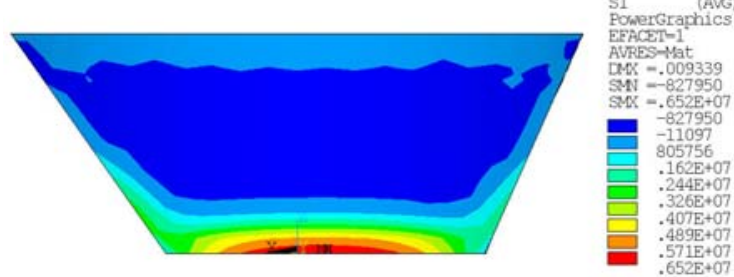

Fig.8 Cloud map of arch dam's first principal stress under case 5(Pa)

We can see from Fig.4 to Fig.8, under case 1, arch dam's maximum first principal stress value is 4.45 MPa, it is located dam bottom. Under case 2 to case 5, arch dam's first principal stress values are larger, maximum first principal stress is $5.41 \mathrm{MPa}$ under case 3, it is located junction of dam bottom and bedrock, this is mainly because water pressure and earthquake effect together.

Deformation Analysis. Through deformation analysis of Dongxi reservoir concrete arch dam, getting cloud maps of radial displacement under various cases, the cloud maps are shown from Fig.9 to Fig.13.

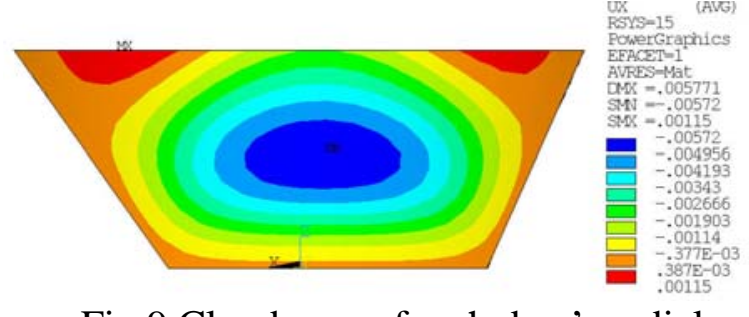

Fig.9 Cloud map of arch dam’s radial displacement under case $1(\mathrm{~m})$

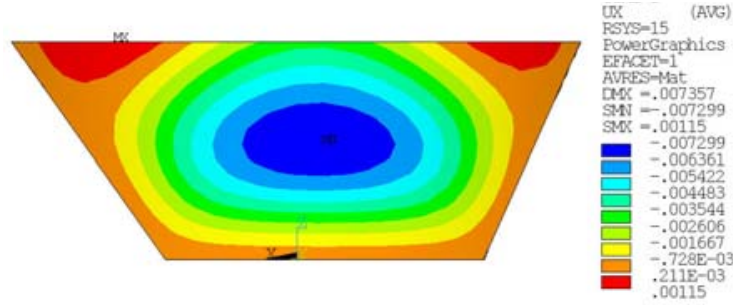

Fig.11 Cloud map of arch dam's radial displacement under case 3(m)

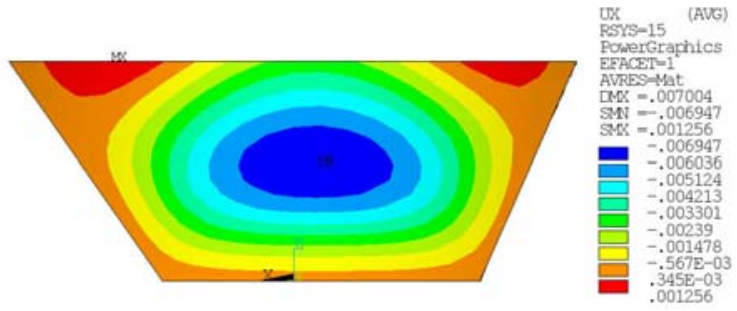

Fig.10 Cloud map of arch dam's radial displacement under case 2(m)

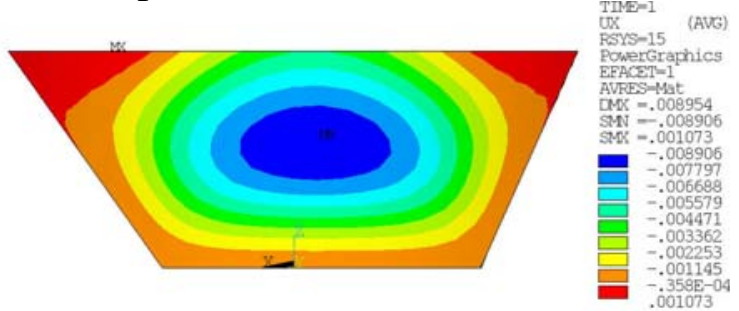

Fig.12 Cloud map of arch dam's radial displacement under case 4(m) 


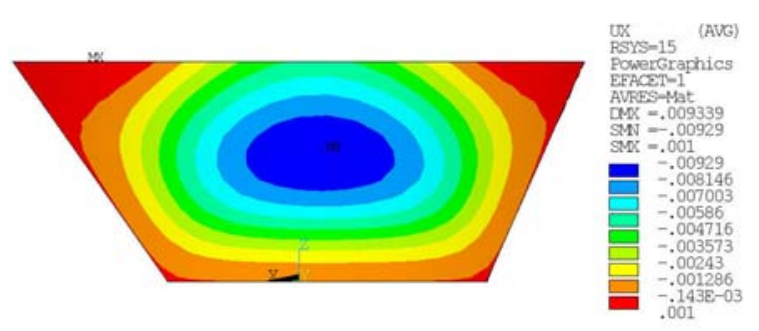

Fig.13 Cloud map of arch dam's radial displacement under case 5(m)

We can see from Fig.9 to Fig.13, under various cases, arch dam's radial displacement values are smaller, and arch dam's radial displacement values exist positive and negative, these mean that arch dam's radial displacements have upstream direction and downstream direction. Under case 1 to case 5, arch dam's radial displacement values are negative, these mean that arch dam's radial displacements are downstream direction, this is mainly because water pressure effect. Under case 5, maximum radial displacement value is $9.29 \mathrm{~mm}$, it is located the middle of dam, this is mainly because flood level and earthquake effect together.

\section{Conclusion}

From the above, arch dam structure has good force performance, stress and displacement values of Dongxi reservoir concrete arch dam are smaller, these can meet design requirements. Research results show that, the arch dam structure design scheme is economic and reasonable, structure is safe and reliable.

\section{References}

[1] GB50010-2002: Design Code for Concrete Structures(China Architecture and Building Press, China 2002)(in Chinese)

[2] M.R. Shen, J.F. Chen: Rock Mechanics(Tongji University Press, China 2006)(in Chinese)

[3] B.F. Zhu: Finite Element Method Principle and Application(China Water Conservancy and Hydropower Press, China 1998)(in Chinese)

[4] B.F. Zhu, J.ZH. Gao, Z.Y. Chen, Y.SH Li: Arch Dam Design and Research(China Water Conservancy and Hydropower Press, China 2002)(in Chinese) 